\title{
Neonatal de-afferentation of capsaicin-sensitive sensory nerves increases in vivo insulin sensitivity in conscious adult rats
}

\author{
S.J.Koopmans ${ }^{1}$, B. Leighton ${ }^{2}$, R. A. DeFronzo ${ }^{1}$ \\ ${ }^{1}$ Department of Medicine, University of Texas Health Science Center, San Antonio, Texas, USA \\ ${ }^{2}$ Department of Biochemistry, University of Oxford, South Parks Road, Oxford, UK
}

Summary Sensory neuropeptides, released from the peripheral nervous system, might modulate glucose homeostasis by antagonizing insulin action. The effects of de-afferentation of functional small diameter unmyelinated C-fibres (sensory nerves) on in vivo insulin-mediated intracellular glucose metabolism were investigated by using euglycaemic insulin (6 and $18 \mathrm{mU} / \mathrm{kg} . \mathrm{min})$ clamps with $\left[3{ }^{3} \mathrm{H}\right]$-glucose infusion in 24 adult rats, treated neonatally with either capsaicin (CAP) $(50 \mathrm{mg} / \mathrm{kg})$ or vehicle $(\mathrm{CON})$. Following the clamp, skeletal muscle groups, liver and adipose tissue were freeze-clamped. At plasma insulin levels of approximately $90 \mathrm{mU} / \mathrm{l}$, CAP-rats showed a $21 \%$ increase in whole body glucose uptake compared with CON $(24.4 \pm 1.6$ vs $20.1 \pm 0.8 \mathrm{mg} / \mathrm{kg} \cdot \mathrm{min}$, $p<0.02$ ), which was paralleled by a $20 \%$ increase in whole body glycolysis ( $12.6 \pm 0.8$ vs $10.5 \pm 0.5 \mathrm{mg} /$ kg.min $p<0.05$ ) (concentration of ${ }^{3} \mathrm{H}_{2} \mathrm{O}$ in plasma). Whole body skeletal muscle glycogenesis was increased by $80 \%$ in CAP-rats $(5.7 \pm 0.7$ vs $3.1 \pm$ $0.7 \mathrm{mg} / \mathrm{kg} \cdot \min , p<0.05)$ with increased muscle glycogen synthase activity. Whole body (muscle, liver and adipose tissue combined) de novo lipogenesis also was increased in CAP-rats compared with CON $(0.69 \pm 0.10$ vs $0.44 \pm 0.06 \mathrm{mg} / \mathrm{kg} \cdot \min , p<0.05)$ (incorporation of $\left[3-{ }^{3} \mathrm{H}\right]$-glucose counts into glycogen or fat). Hepatic glucose production was lower in CAP-rats compared with CON $(0.6 \pm 0.6$ vs $2.1 \pm 0.7 \mathrm{mg} / \mathrm{kg} \cdot \min , p<0.05)$. Plasma glucagon, corticosterone, epinephrine and norepinephrine levels were reduced in CAP-rats: $43 \pm 2$ compared with $70 \pm 6 \mathrm{pg} / \mathrm{ml}, 855 \pm 55$ compared with $1131 \pm 138$ $\mathrm{nmol} / \mathrm{l}, 513 \pm 136 \mathrm{compared}$ with $1048 \pm 164 \mathrm{pmol} / \mathrm{l}$ and $928 \pm 142$ compared with $1472 \pm 331 \mathrm{pmol} / \mathrm{l}$, respectively, $p<0.05$. At plasma insulin levels of approximately $400 \mathrm{mU} / 1$, CAP-rats showed no differences in peripheral and hepatic insulin action compared with CON. We conclude that the removae of endogenous sensory neuropeptides, by de-afferentation of capsaicin-sensitive sensory nerves, increases in vivo insulin sensitivity, but not responsiveness: 1) primarily through an increased sensitivity of skeletal muscle glycogen synthesis to insulin; 2) through a reduction in the levels of counter-regulatory hormones, thereby creating a milieu which favours overall in vivo insulin sensitivity with respect to glucose uptake, glucose production, glycolysis, glycogenesis and lipogenesis. [Diabetologia (1998) 41: 813-820]

Keywords Insulin sensitivity, glycolysis, glycogenesis, lipogenesis, sensory nerves, counter-regulatory hormones.
Received: 10 November 1997 and in revised form 4 March 1998

Corresponding author: S.J. Koopmans, PhD., Department of Endocrinology and Metabolic Diseases, University Hospital C4R, Albinusdreef 2, 2333 AA Leiden, The Netherlands
Abbreviations: CAP, Rats treated neonatally with capsaicin; $\mathrm{CON}$, control rats treated neonatally with vehicle; CGRP, calcitonin-gene related peptide; $\mathrm{Rd}$, whole body glucose uptake; HGP, hepatic glucose production; Ra, rate of glucose appearance; GLY, whole body glycolysis; UDPG, uridine diphosphoglucose; G-6-P, glucose-6-phosphate; ANOVA, analysis of variance. 
Sensory neuropeptides like calcitonin-gene related peptide (CGRP), which are present in the peripheral nervous system, are thought to modulate glucose homeostasis by antagonizing insulin action on skeletal muscle [1,2]. Both in vitro [1] and in vivo [2] studies have shown that treatment with CGRP leads to insulin resistance in muscle glucose metabolism. CGRP is present in motor-end plates [3] and in sensory nerves in skeletal muscle [4] from which CGRP is released after electrical stimulation [5]. Treatment with a high dose of capsaicin, an agent which activates these specific sensory fibres, also results in the release of (among other neuropeptides) CGRP [6] and an inhibition of insulin-stimulated glycogen synthesis in skeletal muscle in a manner which is similar to the action of CGRP [7].

Treatment of newborn rats with a high dose $(50 \mathrm{mg} / \mathrm{kg})$ of capsaicin, causes permanent de-afferentation of functional small-diameter unmyelinated sensory C-fibres that are capsaicin-sensitive. This leads to a substantial decrease $(\approx 90 \%)$ in the content of CGRP $[4,8,9]$. Subsequently, in adult rats which received neonatal capsaicin treatment there is a minimal release of sensory peptides from de-afferenated fibres. When the release of neuropeptides is prevented or inhibited by destruction of sensory nerves, insulin action should increase. Indeed, if capsaicin is given to newborn rats and these rats are allowed to grow to 8-12 weeks of age and then muscles are isolated and incubated in vitro, an increased response of glycogen synthesis to insulin is found [7]. These results suggest the following hypothesis: removal of endogenous CGRP from skeletal muscle by neonatal capsaicin treatment improves insulin sensitivity.

Since the in vivo regulation of carbohydrate metabolism is dependent on the interaction between skeletal muscle, liver and fat tissue, it is of physiological importance to investigate the net in vivo effects of sensory C-fibre ablation on whole body insulinmediated glucose metabolism.

To our knowledge, only one previous in vivo study has examined the involvement of capsaicin-sensitive sensory nerves in the regulation of glucose homeostasis. Zhou et al. [10] showed that neonatal capsaicin treated rats lost the ability to recover quickly from insulin-induced hypoglycaemia compared with vehicletreated control rats.

The aim of the present study was to investigate whether neonatal destruction of neuropeptide containing sensory fibres has any physiological meaning on in vivo skeletal muscle, hepatic and adipose tissue insulin action in adult rats. Tissue specific, intracellular glucose metabolism was investigated by using the hyperinsulinaemic euglycaemic clamp technique in conscious rats [11-13].

\section{Materials and methods}

Animals, capsaicin-treatment and surgery. Sprague Dawley rats (obtained from Charles River, Wilmington, Mass., USA), subjected to a standard light (06.00-18.00 hours) dark (18.00-06.00 hours) cycle in an air-controlled room $\left(23^{\circ} \mathrm{C}\right)$, were bred in the animal quarters of the Health Science Center of the University of Texas. Sensory nerves were destroyed at birth by $50 \mathrm{mg} / \mathrm{kg}$ capsaicin (Sigma Chemical CO. St Louis, Mo., USA) given subcutaneously in the back of the neck. Young rats weight was between 6.8 and $8.2 \mathrm{~g}$ and they received a $50 \mu \mathrm{l}$ solution of $10 \%$ Tween $80,10 \%$ ethanol in saline with or without capsaicin. Leakage was prevented by sealing the injection site with cyanoacrylate-glue. After injection, the rats were placed under a heating lamp until all of them had been treated. The young rats were returned to their mothers and weaned for 4 weeks. After 4 weeks, the rats were housed in individual cages and were given free access to food and water. After 10-12 weeks adult (350-400 g) capsaicin-treated and vehicle-treated (control) rats received a hyperinsulinaemic (6 or $18 \mathrm{mU} / \mathrm{kg} \cdot \mathrm{min})$ euglycaemic clamp with $\left[3-{ }^{3} \mathrm{H}\right]$-glucose to measure in vivo insulin action. The number of rats in each group is shown in Table 1 . The rats were anaesthetized with pentobarbital sodium ( $50 \mathrm{mg} / \mathrm{kg}$ i. p. body weight $) 4-6$ days before the insulin clamp experiments were performed and indwelling catheters were inserted in the right internal jugular vein and in the left carotid artery. Both catheters were exteriorized through the skin at the back of the neck $[11,14]$.

Hyperinsulinaemic euglycaemic clamp studies. After a $24 \mathrm{~h}$ fast, whole body glucose uptake and hepatic glucose production were measured in conscious, unrestrained rats using the hyperinsulinaemic euglycaemic clamp in combination with [3$\left.{ }^{3} \mathrm{H}\right]$-glucose (Du Pont-NEN, Boston, Mass., USA) infusion as described previously [11-14]. During the 120 min hyperinsulinaemic euglycaemic clamps, insulin was given as a prime $(104 \mathrm{mU} / \mathrm{kg} \cdot \min$ over $1 \mathrm{~min})$-continuous $(6 \mathrm{mU} / \mathrm{kg} \cdot \mathrm{min})$ infusion and a variable infusion of a $25 \%$ glucose solution was started and adjusted to maintain the plasma glucose concentration at approximately $5.5 \mathrm{mmol} / \mathrm{l}$. $\left[3-{ }^{3} \mathrm{H}\right]$-glucose was given as a prime $(4.7 \mu \mathrm{Ci})$-continuous $(0.15 \mu \mathrm{Ci} / \mathrm{min})$ infusion. Plasma samples for determination of $\left[3-{ }^{3} \mathrm{H}\right]$-glucose specific activity were obtained at 5-10 min intervals throughout the clamp study. Steady state conditions for plasma $\left[3-{ }^{3} \mathrm{H}\right]$-glucose specific activity were reached within 30 min after initiation of $\left[3-{ }^{3} \mathrm{H}\right]-$ glucose infusion. Plasma samples for insulin, glucagon, epinephrine and norepinephrine, corticosterone, lactate and non-esterified fatty acids were collected at 60 and $120 \mathrm{~min}$. The total amount of blood withdrawn during the studies was less than $5 \mathrm{ml}$. To prevent intravascular volume depletion and anaemia, a solution $(1: 1 \mathrm{v} / \mathrm{v})$ of an equivalent amount of fresh whole blood obtained by heart puncture from littermates of the experimental animal and heparinized saline $(10 \mathrm{U} / \mathrm{ml})$ was infused at a constant rate throughout the clamp study. At the end of the study, rats were injected with sodium pentobarbital (60 mg/kg body weight, i. v.), the abdomen was quickly opened, portal vein blood was taken, and the liver and rectus abdominal muscles were freeze-clamped in situ. Subsequently the psoas, gastrocnemius and soleus muscles and epididymal and peri-renal fat were freeze-clamped with aluminum tongs precooled in liquid nitrogen. All tissue samples were kept frozen at $-80^{\circ} \mathrm{C}$ until analysis.

Whole body glucose uptake (Rd) and hepatic glucose production (HGP). Calculations were made as described previously [11-14]. Plasma $\left[3-{ }^{3} \mathrm{H}\right]$-glucose specific activity was measured in duplicate on the supernatants of $\mathrm{Ba}(\mathrm{OH})_{2}$ and $\mathrm{ZnSO}_{4}$ pre- 
Table 1. Insulin-stimulated rates of tissue specific glycogen synthesis and de novo lipogenesis during the hyperinsulinaemic (insulin infusion rates of 6 and $18 \mathrm{mU} / \mathrm{kg} \cdot \mathrm{min}$ ) euglycae- mic clamp studies in control rats and rats with prior neonatal destruction by capsaicin of neuropeptide containing sensory fibres

\begin{tabular}{|c|c|c|c|c|}
\hline Rat groups ( $n=6$ per group) & Control & Capsaicin & Control & Capsaicin \\
\hline Insulin infusion rate $(\mathrm{mU} / \mathrm{kg} \cdot \mathrm{min})$ & 6 & 6 & 18 & 18 \\
\hline $\begin{array}{l}\text { Muscle glycogenesis } \\
(\mathrm{mg} / \mathrm{kg} \cdot \mathrm{min})\end{array}$ & $3.10 \pm 0.69$ & $5.66 \pm 0.72^{\mathrm{a}}$ & $9.77 \pm 0.79$ & $10.16 \pm 1.02$ \\
\hline $\begin{array}{l}\text { Liver glycogenesis } \\
(\mathrm{mg} / \mathrm{kg} \cdot \mathrm{min})\end{array}$ & $0.19 \pm 0.02$ & $0.21 \pm 0.03$ & $0.41 \pm 0.08$ & $0.36 \pm 0.07$ \\
\hline $\begin{array}{l}\text { Adipocyte glycogenesis } \\
(\mathrm{mg} / \mathrm{kg} \cdot \mathrm{min})\end{array}$ & $0.04 \pm 0.01$ & $0.07 \pm 0.02$ & $0.04 \pm 0.01$ & $0.05 \pm 0.01$ \\
\hline $\begin{array}{l}\text { Total glycogenesis } \\
(\mathrm{mg} / \mathrm{kg} \cdot \min )\end{array}$ & $3.33 \pm 0.69$ & $5.94 \pm 0.72^{a}$ & $10.19 \pm 0.80$ & $10.58 \pm 1.04$ \\
\hline $\begin{array}{l}\text { Muscle de novo lipogenesis } \\
(\mathrm{mg} / \mathrm{kg} \cdot \mathrm{min})\end{array}$ & $0.18 \pm 0.04$ & $0.35 \pm 0.10$ & $0.32 \pm 0.10$ & $0.25 \pm 0.05$ \\
\hline $\begin{array}{l}\text { Liver de novo lipogenesis } \\
(\mathrm{mg} / \mathrm{kg} \cdot \mathrm{min})\end{array}$ & $0.08 \pm 0.01$ & $0.07 \pm 0.01$ & $0.07 \pm 0.01$ & $0.10 \pm 0.02$ \\
\hline $\begin{array}{l}\text { Adipocyte de novo lipogenesis } \\
(\mathrm{mg} / \mathrm{kg} \cdot \mathrm{min})\end{array}$ & $0.18 \pm 0.03$ & $0.27 \pm 0.05$ & $0.40 \pm 0.40$ & $0.47 \pm 0.05$ \\
\hline $\begin{array}{l}\text { Total de novo lipogenesis } \\
(\mathrm{mg} / \mathrm{kg} \cdot \min )\end{array}$ & $0.44 \pm 0.06$ & $0.69 \pm 0.10^{\mathrm{a}}$ & $0.79 \pm 0.12$ & $0.81 \pm 0.09$ \\
\hline
\end{tabular}

cipitated plasma samples (Somogyi procedure) after evaporation to dryness to eliminate ${ }^{3} \mathrm{H}_{2} \mathrm{O}$. The calculations concerning steady-state Rd and HGP were carried out during the last 40 min of $\left[3-{ }^{3} \mathrm{H}\right]$-glucose infusion. During this steady-state period, the rate of glucose appearance $(\mathrm{Ra})$ is equal to the rate of whole body glucose disappearance $(\mathrm{Rd})$, and the glucose turnover rate $(=\mathrm{Ra}=\mathrm{Rd}$ in $\mathrm{mg} / \mathrm{kg} \cdot \mathrm{min}$ ) was calculated by dividing the $\left[3-{ }^{3} \mathrm{H}\right]$-glucose infusion rate $(\mathrm{dpm} / \mathrm{min})$ by the steady-state value of plasma glucose specific activity $(\mathrm{dpm} / \mathrm{mg})$. In the basal state, $\mathrm{Ra}$ ( = whole body glucose uptake) is a reflection of HGP. In the insulin stimulated state, Ra equals HGP plus the rate of exogenous glucose infusion. Therefore $\mathrm{HGP}=\mathrm{Ra}-$ exogenous glucose infusion.

Whole body glycolysis (GLY) and whole body glucose storage. The methodologic details of these measurements have been described previously $[14,15]$. Aliquots of plasma were precipitated with $\mathrm{Ba}(\mathrm{OH})_{2}$ and $\mathrm{ZnSO}_{4}$ and centrifuged. Plasma ${ }^{3} \mathrm{H}_{2} \mathrm{O}$ content was calculated by subtracting the dpm's in an aliquot of the Somogyi supernatant which had been evaporated to dryness from the dpm's of an unevaporated aliquot. ${ }^{3} \mathrm{H}$ in the $\mathrm{C}-3$ position of glucose is lost to $\mathrm{H}_{2} \mathrm{O}$ during glycolysis [16]. Therefore, plasma tritiated counts can be present either as ${ }^{3} \mathrm{H}_{2} \mathrm{O}$ or as $\left[3-{ }^{3} \mathrm{H}\right]$-glucose. Rates of GLY were estimated from the increment per unit time in ${ }^{3} \mathrm{H}_{2} \mathrm{O}(\mathrm{dpm} / \mathrm{l} \cdot \mathrm{min})$ multiplied by body water mass (1) divided by the $\left[3-{ }^{3} \mathrm{H}\right]$-glucose specific activity (DPM/mg). Plasma $\mathrm{H}_{2} \mathrm{O}$ is assumed to be $93 \%$ of the total plasma volume, and total body $\mathrm{H}_{2} \mathrm{O}$ mass to be $65 \%$ of the body weight $[14,15]$. The calculations concerning the rate of GLY were carried out during the last $70 \mathrm{~min}$ of $\left[3-{ }^{3} \mathrm{H}\right]$-glucose infusion. The appearance of ${ }^{3} \mathrm{H}_{2} \mathrm{O}$ in plasma was linear during this time period, as judged by linear regression analysis. This is in accordance with previous findings $[14,15]$. Whole body glucose storage, which primarily reflects glycogen formation (and to a much lesser extent glucose conversion to lipid and lactate), was calculated as whole body glucose uptake (Rd) minus whole body glycolysis (GLY).

Muscle, liver, and adipocyte glycogen synthesis and lipogenesis in vivo. For each rat, the mean of two determinations per rec- tus abdominus, psoas and gastrocnemius muscles, liver, and epididymal and perirenal fat pads was used to describe mean whole body glycogen and lipid synthetic rate. This extrapolation is based upon the observation that the fibre composition of psoas (5\% type $1,40 \%$ type IIa, and $55 \%$ type IIb), rectus abdominus (20\% type IIa and $80 \%$ type IIb) and gastrocnemius (70\% type IIa and $30 \%$ type $\mathrm{IIb}$ ) muscles is representative of the whole body muscle fibre composition in the rat $[17$, 18]. The muscle mass of the rat consists mainly (95\%) of type II fibres [19]. When extrapolating from tissue to whole body, it was assumed that skeletal muscle, liver and adipocytes contributed $40 \%, 4 \%$ and $10 \%$ to whole body weight, respectively $[14,20]$. The rate of glycogen or lipid synthesis was expressed as $\mathrm{mg}$ of glucose units in glycogen or lipid per $\mathrm{kg}$ (net weight) of tissue per min.

The rates of skeletal muscle, liver and adipocyte glycogen or lipid synthesis were calculated by dividing the number of [3$\left.{ }^{3} \mathrm{H}\right]$-glucose counts in glycogen or lipid per $\mathrm{kg}$ tissue by the time weighed mean plasma $\left[3-{ }^{3} \mathrm{H}\right]$-glucose specific activity $(\mathrm{dpm} / \mathrm{mg}$ glucose $)$ during the time period of $\left[3-{ }^{3} \mathrm{H}\right]$-glucose infusion [14]. At the end of the insulin clamp studies a portal vein blood sample was obtained simultaneously with the tissue collection procedure. The $\left[3-{ }^{3} \mathrm{H}\right]$-glucose specific activity in portal blood, was $99 \pm 3 \%$ and $101 \pm 4 \%$ of the peripheral blood tritiated glucose specific activity in control and capsaicin-treated rats, respectively. Since the tritiated glucose specific activity in peripheral blood during the insulin clamp closely reflects the tritiated glucose specific activity in the portal vein blood, it can be used to calculate the liver glycogen synthetic rate. Determination of the net rate of glycogen or lipid synthesis in the aforementioned way includes only the contribution of the direct (from glucose) and not the indirect (C3-fragments) pathway.

Glycogen synthase activity in muscle samples. Glycogen synthase was assayed in duplicate by a modification of the method described by Mandarino et al. [21]. Muscle (soleus and psoas) samples $(25 \mathrm{mg})$ were homogenized in ice-cold buffer $(0.5 \mathrm{ml})$ containing (in mmol/l) 50 potassium phosphate, 2.0 dithiothreitol, 2.0 ethylenediaminetetraacetic acid, 20 sodium fluoride (to inhibit phosphatase activity), and protease inhibitors (in 
mg 1.0 leupeptin, 1.0 trypsin inhibitor, 2.0 p-aminobenzamidine, $3.7 \mathrm{Na}$ - p tosyl-L-lysine chloromethyl ketone, $3.5 \mathrm{~N}$-tosyl-L-phenylalanine chloromethyl ketone, 8.7 phenylmethylsulphonyl fluoride, all per $100 \mathrm{ml}$ buffer). The extract was centrifuged at $10000 \mathrm{~g}$, and the supernatant, which contains more than $95 \%$ of the glycogen synthase activity, was removed, diluted 1:20 with ice-cold buffer and kept on ice for subsequent glycogen synthase assay. The assay was performed in the presence of $1 \%$ glycogen, $0.3 \mathrm{mmol} / \mathrm{l}$ of the substrate uridine diphospho-glucose (UDPG), $0.7 \mu \mathrm{Ci}\left[1{ }^{3} \mathrm{H}\right]-\mathrm{UDPG}$ (Amersham, Buckinghamshire, England) and 0, 0.05, 0.1 or $10 \mathrm{mmol} / \mathrm{l}$ of the allosteric activator glucose 6-phosphate (G-6-P). The reaction was run for $20 \mathrm{~min}$ at $30^{\circ} \mathrm{C}$. For assay blank, tissue supernatant was boiled for $10 \mathrm{~min}$. Maximal glycogen synthase activity was determined at saturating concentrations of G-6-P $(10 \mathrm{mmol} / \mathrm{l})$ and UDPG $(5 \mathrm{mmol} / \mathrm{l}) .0 .3 \mathrm{mmol} / \mathrm{l}$ and $5 \mathrm{mmol} / \mathrm{l}$ of UDPG yielded identical results. The fractional velocity of glycogen synthase is defined as the activity of glycogen synthase assayed at $0,0.05$ or $0.1 \mathrm{mmol} / \mathrm{l} \mathrm{G}-6-\mathrm{P}$ divided by the activity of the enzyme assayed at $10 \mathrm{mmol} / \mathrm{l} \mathrm{G}-6-\mathrm{P}$. Enzyme activity was expressed as nm of UDPG incorporated into glycogen per min per mg extracted protein. Protein concentrations were determined by the Lowry assay.

Chemical determinations. Plasma glucose was measured by the glucose oxidase method (Glucose Analyser; Beckman Instruments, Fullerton, Calif., USA) and plasma insulin by radioimmunoassay using porcine insulin standards. Plasma lactate concentration was measured spectrophotometrically. Plasma non-esterified fatty acid concentration was determined by an enzymatic calorimetric method using a commercial kit (NEFA C, Wako, Richmond, Va., USA). Plasma glucagon concentration was determined by a double antibody radioimmunoassay (Glucagon Double Antibody, Diagnostic Products, Los Angeles, Calif., USA). The concentrations of epinephrine and norepinephrine were measured by a radioenzymatic catechol-O-methyltransferase procedure as described previously [22] and plasma corticosterone was assayed according to a competitive protein-binding method [22]. Methods for the determination of plasma $\left[3-{ }^{3} \mathrm{H}\right]$-glucose specific activity have been described previously [11-15]. Plasma proteins were precipitated by $\mathrm{Ba}(\mathrm{OH})_{2}$ and $\mathrm{ZnSO}_{4}$ (Somogyi procedure), the supernatants evaporated to dryness at $55^{\circ} \mathrm{C}$ to eliminate ${ }^{3} \mathrm{H}_{2} \mathrm{O}$, reconstituted in $0.1 \mathrm{ml}$ of water, mixed with $5 \mathrm{ml}$ of scintiverse II (Fisher, Pittsburgh, Pa., USA) and counted in a Beckman LS 6000 IC beta scintillation counter (Beckman, Fullerton, Calif., USA). All samples were run in duplicate. Plasma ${ }^{3} \mathrm{H}_{2} \mathrm{O}$ radioactivity was calculated by subtracting the dpms in an aliquot of the Somogyi supernatant which had been evaporated to dryness from an unevaporated aliquot.

Glycogen concentration was determined in duplicate in tissue homogenates after digestion with amyloglucosidase as described previously [14]. The intra-assay and inter-assay coefficients of variation for muscle and liver glycogen were $<10 \%$. The number of tritiated glucose counts in muscle, liver and adipocyte glycogen was determined as previously described [23]. $250 \mathrm{mg}$ of tissue was homogenized in $1 \mathrm{ml}$ of $100 \mathrm{mmol} / \mathrm{l}$ phosphate buffer $\mathrm{pH} 7.4$ containing protease inhibitors and a $125 \mu \mathrm{l}$ aliquot of the supernatant of the tissue homogenates was used to determine the amount of tritium label in glycogen. Glycogen was precipitated on Whatman no. 1 filter paper by washing in absolute ethanol at $-20^{\circ} \mathrm{C}$ for $30 \mathrm{~min}$. The washing procedure was repeated two more times and the filter paper was placed in acetone for $5 \mathrm{~min}$, air dried, and counted in a beta scintillation counter.

To determine the number of tritiated glucose counts in lipid of skeletal muscle, liver and adipose tissue, approximately $1 \mathrm{~g}$

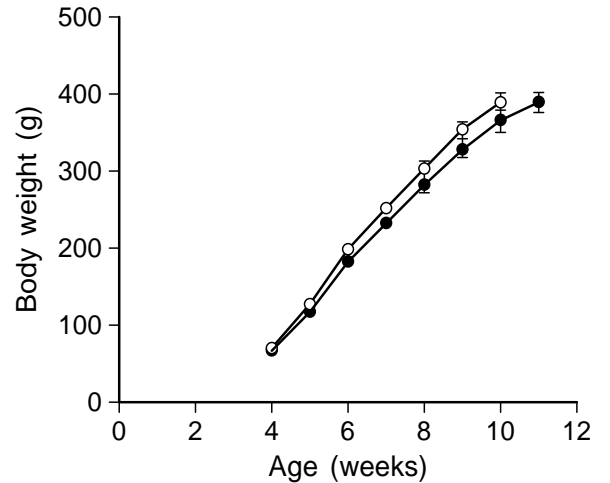

Fig. 1. Growth curves of neonatally capsaicin (CAP) (O) and vehicle $(\mathrm{CON})(\bigcirc)$ treated rats. $n=12$ rats per group

of tissue was homogenized in $3 \mathrm{ml}$ of phosphate buffered saline. $6 \mathrm{ml}$ of a chloroform : methanol solution $(1: 2 \mathrm{v} / \mathrm{v})$ was added and vortexed for $5 \mathrm{~min}$. Subsequently $2 \mathrm{ml}$ of chloroform was added, vortexed for $5 \mathrm{~min}$ and $2 \mathrm{ml}$ of water was added and vortexed for $5 \mathrm{~min}$. The samples were centrifuged for $10 \mathrm{~min}$ at $3000 \mathrm{rev} / \mathrm{min}$. The upper aqueous layer and the middle protein layer were separated from the lower lipid containing chloroform fraction. The chloroform fraction was evaporated to dryness and counted.

Statistical analyses. Analysis of variance (ANOVA) was used for multiple comparison purposes. When ANOVA showed a significant difference among several groups, Fisher's least-significant difference test was used for comparisons between groups. Comparisons between just two groups were performed using the unpaired Student's $t$-test. The criterion for significance was set at $p$ less than 0.05 . All data are presented as the means \pm SEM.

\section{Results}

The growth curves of neonatally capsaicin (CAP) and vehicle $(\mathrm{CON})$ treated rats is shown in Figure 1. CAP rats exhibited a slightly slower growth rate, resulting in similar body weights for 10 -week-old $\mathrm{CON}$ rats compared with 11-week-old CAP rats. The insulin clamp studies were performed when body weights were similar in CON rats (10-11 weeks after birth) and CAP rats (11-12 weeks after birth). Body weights were $392 \pm 11$ and $398 \pm 9 \mathrm{~g}$ in CON rats during the 6 and $18 \mathrm{mU} / \mathrm{kg} \cdot \min$ clamps and $385 \pm 7$ and $371 \pm 7 \mathrm{~g}$ in CAP rats, respectively. Average food and water intake, as measured during a 2 -week period (9-11 weeks of age) were similar among rats. Daily food intake was $24.2 \pm 2.4$ compared with $23.2 \pm 1.9$ $\mathrm{g}$ and water intake was $37.2 \pm 2.2$ compared with $37.5 \pm 2.1 \mathrm{ml}$, in CON compared with CAP rats, respectively.

In vivo insulin-mediated glucose metabolism, as measured at physiological $(\approx 90 \mathrm{mU} / \mathrm{l})$ and supraphysiological $(\approx 400 \mathrm{mU} / \mathrm{l})$ insulin concentrations is shown in Figure 2 to 4 . At plasma insulin levels of approximately $90 \mathrm{mU} / 1$, CAP rats showed a $21 \%$ in- 


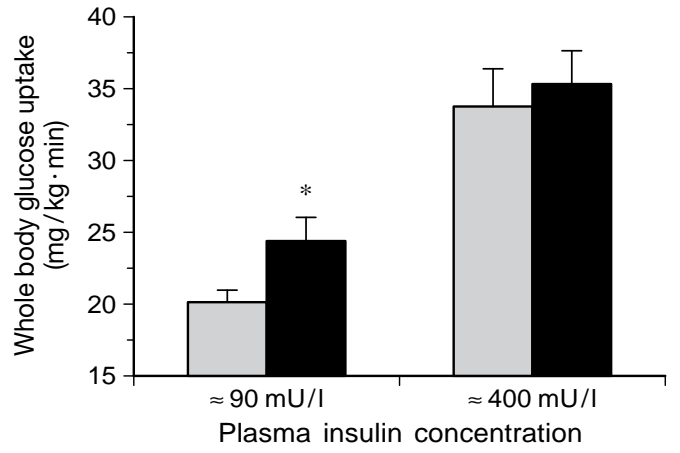

Fig. 2. Insulin-stimulated (insulin infusion rates of 6 and $18 \mathrm{mU} / \mathrm{kg} \cdot \mathrm{min}$ ) whole body glucose uptake, as measured by the rate of disappearance of $3-{ }^{3} \mathrm{H}$-glucose from plasma during hyperinsulinaemic euglycaemic clamps in neonatally capsaicin (CAP) (shaded bars) and vehicle (CON) (open bars) treated rats. $n=6$ rats per group. ${ }^{*} p<0.02$ compared with $\mathrm{CON}$ rats

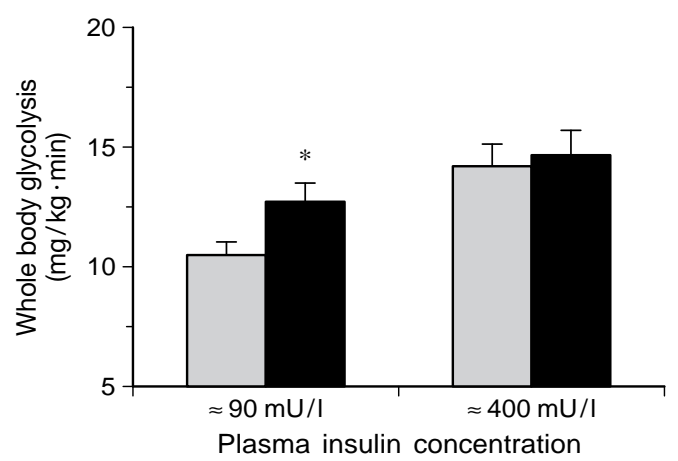

Fig. 3. Insulin-stimulated (insulin infusion rates of 6 and $18 \mathrm{mU} / \mathrm{kg} . \mathrm{min}$ ) whole body glycolysis, as measured by the rate of appearance of ${ }^{3} \mathrm{H}_{2} \mathrm{O}$ in plasma during hyperinsulinaemic euglycaemic clamps in neonatally capsaicin (CAP) (shaded bars) and vehicle (CON) (open bars) treated rats. $n=6$ rats per group. $* p<0.05$ compared with CON rats.

crease in whole body glucose uptake compared with CON rats $(24.4 \pm 1.6$ vs $20.1 \pm 0.8 \mathrm{mg} / \mathrm{kg} \cdot \mathrm{min}, p<$ 0.02) (Fig. 2), and this was accounted for by parallel increases in whole body glycolysis $(12.6 \pm 0.8$ vs $10.5 \pm 0.5 \mathrm{mg} / \mathrm{kg} \cdot \min , \Delta=20 \%, p<0.05$ ) (Fig. 3 ) and in whole body glucose storage $(11.8 \pm 0.9$ vs $9.6 \pm 0.7 \mathrm{mg} / \mathrm{kg} \cdot \min , \Delta=23 \%, p<0.05)$ (Fig. 4). Hepatic glucose production was lower in CAP compared with $\mathrm{CON}$ rats during the $6 \mathrm{mU} / \mathrm{kg} \cdot \mathrm{min}$ insulin clamp study $(0.6 \pm 0.6$ vs $2.1 \pm 0.7 \mathrm{mg} / \mathrm{kg} \cdot \min , p<$ $0.05)$ but was similar and not significantly different from zero during the higher dose insulin clamp study. Maximum insulin responsiveness (measured at a plasma insulin concentration of $\approx 400 \mathrm{mU} / \mathrm{l}$ ) for glucose uptake, glycolysis, glucose storage and hepatic glucose output was similar in CAP and CON rats. The results indicate increased insulin sensitivity but normal insulin responsiveness in CAP rats.

Insulin infusion rates of 6 and $18 \mathrm{mU} / \mathrm{kg} \cdot \mathrm{min}$ resulted in comparable steady state plasma insulin lev-

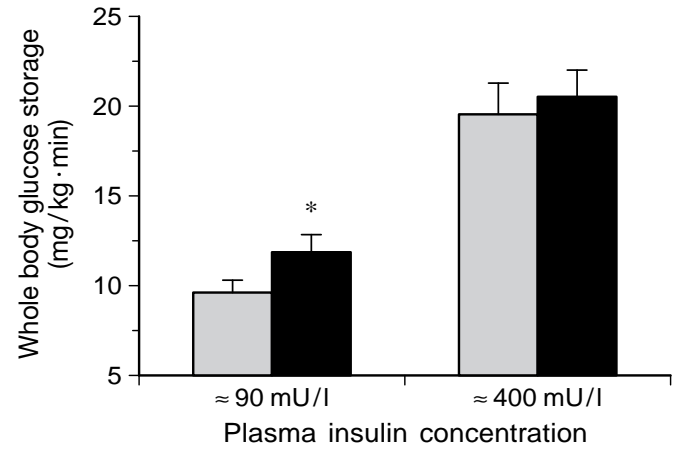

Fig. 4. Insulin-stimulated (insulin infusion rates of 6 and $18 \mathrm{mU} / \mathrm{kg} \cdot \mathrm{min}$ ) whole body glucose storage ( = whole body glucose uptake minus glycolysis) in neonatally capsaicin (CAP) (shaded bars) and vehicle (CON) (open bars) treated rats. $n=6$ rats per group. ${ }^{*} p<0.05$ compared with CON rats

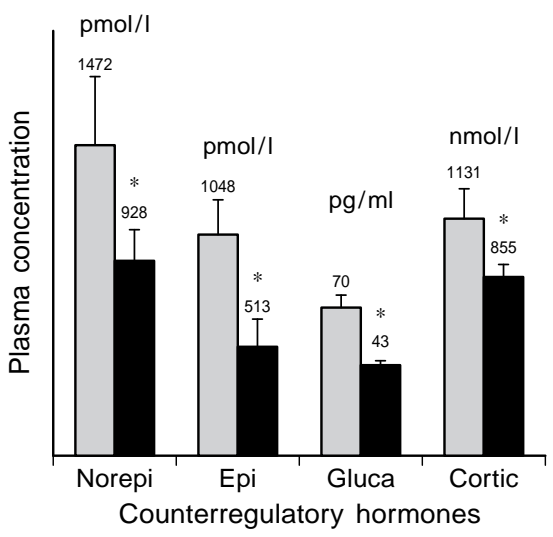

Fig.5. Plasma counter-regulatory hormone concentrations during the $6 \mathrm{mU} / \mathrm{kg} \cdot \mathrm{min}$ insulin clamp in neonatally capsaicin (CAP) (shaded bars) and vehicle (CON) (open bars) treated rats. $n=6$ rats per group. ${ }^{*} p<0.05$ compared with CON rats. Norepi $=$ Norepinephrine $;$ Epi $=$ Epinephrine $;$ Gluca $=$ Glucagon; Cortic $=$ Corticosterone

els among CON (90 \pm 6 and $406 \pm 41 \mathrm{mU} / \mathrm{l})$ and CAP $(85 \pm 5$ and $369 \pm 30 \mathrm{mU} / \mathrm{l})$ rats, respectively. The coefficient of variation in plasma glucose levels during the euglycaemic insulin clamp studies was less than $5 \%$ (range $5.4 \pm 0.2$ to $5.7 \pm 0.1 \mathrm{mmol} / \mathrm{l}$ ), indicating the maintenance of normoglycaemia despite the presence of hyperinsulinaemia.

CAP rats had significantly lower levels of glucagon, catecholamines and corticosterone during the $6 \mathrm{mU} / \mathrm{kg} \cdot \mathrm{min}$ insulin clamp study (Fig.5). Plasma norepinephrine $(2678 \pm 384$ vs $1897 \pm 390 \mathrm{pmol} / \mathrm{l})$, epinephrine $(961 \pm 229$ vs $469 \pm 76 \mathrm{pmol} / \mathrm{l})$ and corticosterone $(1104 \pm 166$ vs $662 \pm 83 \mathrm{nmol} / \mathrm{l})$ (all $p<$ $0.05)$, but not glucagon levels ( $39 \pm 2 \mathrm{vs} 46 \pm 6 \mathrm{pg} / \mathrm{ml})$ were also significantly lower in CAP rats during the high dose insulin clamp. Plasma non-esterified fatty acid levels were lower in CAP rats $(0.97 \pm 0.14$ vs $0.56 \pm 0.02 \mathrm{mmol} / 1, p<0.05)$ during the lower dose insulin clamp but similar to CON rats at the higher in- 
Table 2. In vitro glycogen synthase activity in soleus (type I) and psoas (type II) muscle. Muscles were freeze-clamped at the end of hyperinsulinaemic (insulin infusion rates $=6$ and $18 \mathrm{mU} / \mathrm{kg} \cdot \mathrm{min}$ ) euglycaemic clamp studies in control rats and rats with prior neonatal destruction by capsaicin of neuropeptide containing sensory fibres. Fractional velocity (FV\%) of glycogen synthase was defined as glycogen synthase activity assayed at $0,0.05$ or $0.1 \mathrm{mmol} / 1$ glucose-6-phosphate $(\mathrm{G} 6 \mathrm{P})$ divided by maximum glycogen synthase activity at $10 \mathrm{mmol} / \mathrm{l}$ $\mathrm{G} 6 \mathrm{P}\left(\mathrm{V}_{\max }\right.$ in nmoles UDP-glucose incorporated into glycogen per min per mg muscle protein)

\begin{tabular}{lccll}
\hline Rat groups $(n=6$ per group) & Control & Capsaicin & Control & Capsaicin \\
\hline Insulin infusion rate $(\mathrm{mU} / \mathrm{kg} \cdot \mathrm{min})$ & 6 & 6 & 18 & 18 \\
Soleus (FV\%) at $0 \mathrm{mmol} / \mathrm{l} \mathrm{G} 6 \mathrm{P}$ & $6 \pm 2$ & $7 \pm 1$ & $11 \pm 2$ & $12 \pm 3$ \\
Soleus $(\mathrm{FV} \%$ ) at $0.1 \mathrm{mmol} / \mathrm{l} \mathrm{G} 6 \mathrm{P}$ & $47 \pm 4$ & $56 \pm 2^{\mathrm{a}}$ & $46 \pm 3$ & $63 \pm 4^{\mathrm{c}}$ \\
Soleus $\mathrm{V}_{\max }$ at $10 \mathrm{mmol} / \mathrm{l} \mathrm{G} 6 \mathrm{P}$ & $32 \pm 4$ & $35 \pm 4$ & $37 \pm 4$ & $36 \pm 5$ \\
Psoas $(\mathrm{FV} \%$ ) at $0 \mathrm{mmol} / \mathrm{l} \mathrm{G6P}$ & $12 \pm 1$ & $13 \pm 2$ & $11 \pm 2$ & $15 \pm 3$ \\
Psoas $(\mathrm{FV} \%$ ) at $0.05 \mathrm{mmol} / \mathrm{l} \mathrm{G} 6 \mathrm{P}$ & $35 \pm 3$ & $47 \pm 3^{\mathrm{b}}$ & $37 \pm 9$ & $44 \pm 5$ \\
Psoas $\mathrm{V}_{\max }$ at $10 \mathrm{mmol} / \mathrm{l} \mathrm{G} 6 \mathrm{P}$ & $9 \pm 2$ & $10 \pm 2$ & $21 \pm 2$ & $33 \pm 6^{\mathrm{a}}$ \\
\hline
\end{tabular}

${ }^{\mathrm{a}} p<0.05,{ }^{\mathrm{b}} p<0.025,{ }^{\mathrm{c}} p<0.005$ compared with the corresponding control rats

sulin infusion $(0.60 \pm 0.03$ vs $0.54 \pm 0.06 \mathrm{mmol} / \mathrm{l})$. Plasma lactate levels were similar in CON and CAP rats during the 6 and $18 \mathrm{mU} / \mathrm{kg} . \mathrm{min}$ insulin clamp study $(0.91 \pm 0.05$ compared with $1.21 \pm 0.16$ and $2.30 \pm 0.30$ vs $1.82 \pm 0.19 \mathrm{mmol} / \mathrm{l}$, respectively).

Table 1 shows the insulin-stimulated rates of tissue (skeletal muscle, liver and adipose tissue) glycogenesis and de novo lipogenesis. Insulin-mediated stimulation of both total tissue glycogenesis and de novo lipogenesis were significantly increased in CAP rats during the 6 but not $18 \mathrm{mU} / \mathrm{kg} \cdot \min$ insulin clamp. The major factor responsible for the increase in whole body glucose storage is skeletal muscle glycogen synthesis, which was increased by $80 \%$ in CAP compared to $\mathrm{CON}$ rats $(5.7 \pm 0.7$ vs $3.1 \pm 0.7 \mathrm{mg} /$ $\mathrm{kg} \cdot \min , p<0.05)$. Both muscle and adipose tissue contributed to the increase in total body lipogenesis.

The concentrations of glycogen in skeletal muscle and liver at the end of the clamp studies were not different in CON compared with CAP rats $(8.0 \pm 0.5$ and $2.9 \pm 0.2$ vs $8.5 \pm 0.3$ and $2.9 \pm 0.2$ during the $6 \mathrm{mU} /$ $\mathrm{kg} \cdot \min$ clamp and $10.8 \pm 0.5$ and $3.1 \pm 0.3$ vs $11.0 \pm 0.8$ and $4.1 \pm 0.5 \mathrm{mg}$ of glycogen per gram of tissue during the $18 \mathrm{mU} / \mathrm{kg} \cdot \mathrm{min}$ clamp, respectively). Liver weights were similar in CON $(15.3 \pm 0.4 \mathrm{~g})$ compared with CAP $(14.8 \pm 0.4 \mathrm{~g})$ rats.

In Table 2, the activity of skeletal muscle glycogen synthase is shown. Soleus (type I muscle) and psoas (type II muscle) muscles were studied and both muscle types showed increased glycogen synthase activity in CAP compared with CON rats.

\section{Discussion}

At physiologic insulin concentrations in vivo insulinmediated glucose metabolism was increased in neonatal capsaicin treated (CAP) rats whereas at supraphysiologic insulin concentrations insulin-mediated glucose metabolism was virtually identical in the CAP and CON groups. These results indicate that capsaicin treatment enhances insulin sensitivity but has no effect on insulin responsiveness. From a quantitative standpoint both whole body glycolysis (increment of $2.1 \mathrm{mg} / \mathrm{kg} \cdot \mathrm{min}$, or $20 \%$ ) and whole body glucose storage (increment of $2.2 \mathrm{mg} / \mathrm{kg} \cdot \mathrm{min}$, or $23 \%$ ) contributed equally to the increment in insulin-mediated whole body glucose uptake (increment of $4.3 \mathrm{mg} / \mathrm{kg} \cdot \mathrm{min}$, or $21 \%$ ). From a qualitative standpoint, skeletal muscle glycogen synthesis accounted for the majority of the increase in whole body glucose storage and glucose uptake in CAP treated rats (Table 1). The increase in muscle glycogenesis was accompanied by an increase in glycogen synthase activity in CAP rats (Table 2). Although insulin-stimulated whole body lipogenesis also was increased in CAP treated rats, its contribution to the increase in total body glucose storage was relatively small compared with that of muscle glycogen synthesis. A number of potential explanations could account for the improvement in insulin sensitivity in CAP rats. Most noteable was the decline in insulin antagonistic hormones. Plasma catecholamine concentrations measured during both the 6 and $18 \mathrm{mU} /$ $\mathrm{kg} \cdot \min$ insulin clamps, were 1.5 to 2-fold lower in CAP compared with CON rats. This is consistent with previous publications which indicated that the baseline levels of catecholamines may be regulated by capsaicin-sensitive nerves [24,25]. From our previous work [22] we know that hyperinsulinaemia, in the absence of changes in glycaemia, is able to stimulate the sympathetic nervous system, as reflected by an increase in plasma norepinephrine (but not epinephrine) levels. By comparing the plasma catecholamine concentrations during the low and high dose insulin clamp studies, it is clear that insulin is still able to stimulate the sympathetic nervous system in CAP rats (norepinephrine levels are 2-fold higher at insulin levels of $\approx 400 \mathrm{mU} / 1$ compared with $\approx 90 \mathrm{mU} / 1$, $p<0.05)$. However, during both insulin infusion steps both the plasma epinephrine and norepinephrine levels were significantly reduced in CAP compared with CON rats. Because basal catecholamine levels were not measured in this study, we can not define whether 
the lower epinephrine and norepinephrine levels observed during hyperinsulinaemia in CAP rats represents a blunted response to insulin or a reduction in baseline sympathetic nervous system activity. Nonetheless, it is clear that destruction of capsaicin-sensitive nerves results in a diminished activity of the sympathetic nervous system but that the sympathetic nervous system still can be stimulated by insulin.

Plasma corticosterone and glucagon also were reduced in CAP rats. For corticosterone, this accords with reports that capsaicin-sensitive afferent neurons participate in stress-induced and peripheral neuronal stimulation of ACTH release [26, 27]. For glucagon, no other data are available.

In summary, the reduction in the measured levels of counter-regulatory hormones induced by destruction of capsaicin-sensitive nerves favours a hormonal milieu which enhances in vivo insulin action by dimunition of their stimulatory effect on hepatic glucose production and removal of this inhibitory action on whole body glucose disposal.

The reduced levels of plasma non-esterified fatty acids (NEFA) also may contribute to the improvement in insulin-mediated suppression of hepatic glucose production and stimulation of whole body glucose uptake. A decreased supply of NEFA's to the liver is thought to reduce hepatic glucose production [28], while a reduction in plasma NEFA concentration has been shown to enhance insulin sensitivity in muscle. The lower plasma NEFA levels could be explained by the reduction in plasma counter-regulatory hormones which are lipolytic. The enhancement in whole body de novo lipogenesis also could occur secondarily to the decrease in counter-regulatory hormones and could contribute to the reduction in circulating plasma NEFA levels. It can not be excluded that the effects of neonatal capsaicin-treatment on lipogenesis and plasma non-esterified fatty acid concentrations may result from a direct effect of capsaicin on adipose tissue sensory nerves. Consistent with this, it has been reported that inguinal and dorsal subcutaneous fat depots in rats contain sensory nerve terminals [29] which are sensitive to capsaicin.

Differences in body weight and the degree of obesity have a major impact on in vivo insulin sensitivity. Therefore, we matched the body weights of the rats by clamping CAP rats at approximately 12 weeks of age and CON rats at approximately 11 weeks of age. Age, however, also affects insulin sensitivity [30], although to a lesser extent than obesity. In the present study the CAP rats were approximately 1 week older than the CON rats. Therefore, if at all, we would have underestimated the increase in insulin sensitivity in CAP rats.

There is good evidence that capsaicin produces a specific destruction of most of the sensory C-fibres. Moreover, it is well documented that this destruction leads to a depletion of peripheral CGRP and other neuropeptides [31, 32]. Therefore, it is reasonable to suggest that the increases in in vivo insulin sensitivity of CAP rats are caused, at least in part, by a longterm reduction in the content and release of $\mathrm{C}$-fibre CGRP and perhaps other sensory neuropeptides. It is interesting that CAP rats demonstrated an increased insulin sensitivity for the suppression of hepatic glucose production whereas the liver is reported not to contain CGRP $[33,34]$. It is likely that the increase in hepatic insulin sensitivity is not a direct result of the destruction of sensory C-fibres in the liver but of the reduced levels of plasma counter-regulatory hormones, in particular, glucagon and epinephrine which are powerful stimulators of hepatic glucose production or the reduction in plasma NEFA levels or both. CGRP-like immunoreactivity has been found in the pancreas $[9,33,34]$ and is reduced by $60-100 \%$ following capsaicin treatment $[9,34]$. This raises the possibility that $\mathrm{C}$-sensory fibres and CGRP are involved in the regulation of glucagon secretion.

Taken together, the present results raise the possibility that excessive CGRP could contribute to the development of insulin resistance in some animal models. Further in vivo experiments are needed to define the effects of inhibition of CGRP release from sensory nerves on insulin-mediated glucose metabolism, utilizing specific CGRP receptor antagonists [35] and capsaicin receptor antagonists [5]. The use of such antagonists and neonatal capsaicin treatment will help to define more clearly the role of CGRP and other neuropeptides in animal models of insulin resistance.

In summary, de-afferentation of neuropeptidecontaining sensory nerves by capsaicin: 1 ) increases in vivo insulin sensitivity, but not responsiveness, mainly through an increase in skeletal muscle glycogen synthesis and; 2) reduces circulating levels of counter-regulatory hormones, thereby creating a milieu which favours overall in vivo insulin action with respect to stimulation of whole body glucose uptake, glycolysis, glycogenesis, lipogenesis and suppression of hepatic glucose production.

Acknowledgements. The authors thank Donna Banduch, Cindy Munoz, Sheila Taylor, Ivo Que, Chris van der Bent, Tico Petronilia and Sietske Rooijakkers for their excellent technical assistance. This research was supported by a grant from the Dutch Diabetes Research Foundation and by funds from the VA Medical Research fund.

\section{References}

1. Leighton B, Foot EA, Cooper GJS, King JM (1989) Calcitonin gene-related peptide-1 (CGRP-1) is a potent regulator of glycogen metabolism in rat skeletal muscle. FEBS Lett 249: 357-361

2. Choi SB, Frontoni S, Rossetti L (1991) Mechanism by which calcitonin gene-related peptide antagonizes insulin action in vivo. Am J Physiol 260:E321-E325 
3. Forsgren S, Bergh A, Carlsson E, Thornell LE (1993) Calcitonin gene-related peptide expression at endplates of different fibre types in muscles in rat hind limbs. Cell Tissue Res 274: 439-446

4. Rodrigo J, Polak JM, Fernandez L, Ghatei MA, Mulderry P, Bloom SR (1985) Calcitonin gene-related peptide immunoreactive sensory and motor nerves of the rat, cat, and monkey esophagus. Gastroenterology 88: 444-451

5. Sakaguchi M, Inaishi Y, Kashihara Y, Kuno M (1991) Release of calcitonin gene-related peptide from nerve terminals in rat skeletal muscle. J Physiol 434: 257-270

6. Holzer P (1988) Local effector functions of capsaicin-sensitive sensory nerve endings: involvement of tachykinins, calcitonin gene-related peptide and other neuropeptides. Neuroscience 24: 739-768

7. Leighton B, Foot A (1995) The role of the sensory peptide calcitonin-gene-related peptide(s) in skeletal muscle carbohydrate metabolism: effects of capsaicin and resiniferatoxin. Biochem J 307: 707-712

8. Jancs G, Kiraly E, Jancsó, Gábor A (1977) Pharmacologically induced selective degeneration of chemosensitive primary sensory neurons. Nature 270: 741-743

9. Sternini C, Brecha N (1986) Immunocytochemical identification of islet cells and nerve fibres containing calcitonin gene-related peptide-like immunoreactivity in the rat pancreas. Gastroenterology 90: 1155-1163

10. Zhou XF, Jhamandas KH, Livett BG (1990) Capsaicin-sensitive nerves are required for glucostasis but not for catecholamine output during hypoglycaemia in rats. Am J Physiol 258:E212-E219

11. Smith D, Rossetti L, Ferrannini E et al. (1987) In vivo glucose metabolism in the awake rat. Tracer and insulin clamp studies. Metabolism 36: 1167-1174

12. Koopmans SJ, de Boer SF, Sips HCM, Radder JK, Frölich M, Krans HMJ (1991) Whole body and hepatic insulin action in normal, starved and diabetic rats. Am J Physiol 260:E825-E832

13. Koopmans SJ, Maassen JA, Radder JK, Frölich M, Krans HMJ (1992) In vivo insulin responsiveness for glucose uptake at eu- and hyperglycemic levels in normal and diabetic rats. Biochim Biophys Acta 1115: 230-238

14. Rossetti L, A Giaccari (1990) Relative contribution of glycogen synthesis and glycolysis to insulin-mediated glucose uptake. J Clin Invest 85: 1785-1792

15. Giaccari A, L Rossetti (1992) Predominant role of gluconeogenesis in the hepatic glycogen repletion of diabetic rats. J Clin Invest 89: 36-45

16. Ferrannini E, Del Prato S, DeFronzo RA (1985) Glucose kinetics: tracer methods. In: Larner J, Pohl S (eds) Methods in diabetes research, vol II. John Wiley, New York, pp 62-84

17. Müntener M, Srihari T (1983) Changes of myosin and its ATPase in experimentally induced fibre transformation in the rat. Exp Neurol 80: 471-478

18. Hardin DS, Dominguez JH, Garvey WT (1993) Muscle group-specific regulation of GLUT 4 glucose transporters in control, diabetic, and insulin-treated diabetic rats. Metabolism 42: 1310-1315

19. Armstrong RB, Phelps RO (1984) Muscle fibre type composition of the rat hindlimb. Am J Anatomy 171: 259-272
20. Curtis-Prior PB, Trethewey J, Stewart GA, Hanley T (1969) The contribution of different organs and tissues of the rat to assimilation of glucose. Diabetologia 5: 384-391

21. Mandarino LJ, Wright KS, Verity LS et al. (1987) Effects of insulin infusion on human skeletal muscle pyruvate dehydrogenase, phosphofructokinase, and glycogen synthase. J Clin Invest 80: 655-663

22. Koopmans SJ, de Boer SF, Radder JK, Frolich M, Krans HMJ (1993) Counter-regulatory hormone responses during graded hyperinsulinaemic euglycaemia in conscious rats. Physiol Behav 54: 1141-1148

23. Mandarino LJ, Consoli A, Jain A, Kelley DE (1993) Differential regulation of intracellular glucose metabolism by glucose and insulin in human muscle. Am J Physiol 265:E898-E905

24. Khalil Z, Marley PD, Livett BG (1984) Neonatal capsaicin treatment prevents insulin-stress induced adrenal catecholamine secretion in vivo: possible influence on sensory nerves containing substance P. Neurosci Lett 45: 65-70

25. Amann R, Lembeck F (1986) Capsaicin sensitive afferent neurons from peripheral glucose receptors mediate the insulin-induced increase in adrenaline secretion. NaunynSchmiedeberg's Arch Pharmacol 334: 71-76

26. Lembeck F, Amann R (1986) The influence of capsaicin sensitive neurons on stress-induced release of ACTH. Brain Res Bull 16: 541-543

27. Donnerer J, Lembeck F (1988) Neonatal capsaicin treatment of rats reduces ACTH secretion in response to peripheral neuronal stimuli but not to centrally acting stressors. Br J Pharmacol 94: 647-652

28. Foley JE (1992) Rationale and application of fatty acid oxidation inhibitors in the treatment of diabetes mellitus. Diabetes Care 15: 773-784

29. Fishman RB, Dark J (1987) Sensory innervation of white adipose tissue. Am J Physiol 253:R942-R944

30. Leighton B, Dimitriadis GD, Parry-Billings M, Lozeman FJ, Newsholme EA (1989) Effects of aging on the responsiveness and sensitivity of glucose metabolism to insulin in the incubated soleus muscle isolated from Sprague-Dawley and Wistar rats. Biochem J 261: 383-387

31. Wharton J, Gulbenkian S, Mulderry PK et al. (1986) Capsaicin induces a depletion of calcitonin gene-related peptide (CGRP)-immunoreactive nerves in the cardiovascular system of the guinea pig and rat. J Auton Nerv Syst 16: 289-309

32. Geppetti P, Frilli S, Renzi D et al. (1988) Distribution of calcitonin gene-related peptide-like immunoreactivity in various rat tissues: correlation with substance $\mathrm{P}$ and other tachykinins and sensitivity to capsaicin. Regulatory Peptides 23: 289-298

33. Okimura Y, Chihara K, Abe H et al. (1987) Calcitonin gene-related peptide-like immunoreactivity in the central nervous system and peripheral organs of rats. Regulatory Peptides 17: 327-337

34. Sternini C, Reeve JR, Brecha N (1987) Distribution and characterization of calcitonin gene-related peptide immunoreactivity in the digestive system of normal and capsaicin-treated rats. Gastroenterology 93: 852-862

35. Chiba T, Yamaguchi A, Yamatani T et al. (1989) Calcitonin gene-related peptide receptor antagonist human CGRP(8-37). Am J Physiol 256:E331-E335 